\title{
Academic performance of final year medical students at kerbala medical college
}

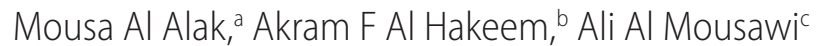

\author{
aDepartment of Gynecology and Obstetrics, College of Medicine, University of Kerbala, Iraq. \\ bDepartment of Surgery, College of Medicine, University of Kerbala, Iraq. \\ 'Department of Family and Community Medicine, College of Medicine, University of Kerbala, Iraq. \\ Correspondence to Mousa Al Alak (email: dr.mousaobgyn@gmail.com). \\ (Submitted: 25 October 2016 - Revised version received: 27 November 2016 - Accepted: 29 November 2016 - Published online: 26 March 2017)
}

\begin{abstract}
Objective Assessment of final year students' examination results in Kerbala Medical College in the academic years 2014-2015 and 2015-2016.

Methods Students' achievements in different parts of the final year examination in Kerbala Medical College for the academic years 2014-2015 and 2015-2016. Students'scores in different parts of the theoretical and clinical examinations were analyzed to determine the effectiveness of the assessment process. In addition, students' cumulative scores for the preceding 5 years were explored to determine the association with final year scores. The data were analyzed using the (SPSS) version 20 through different descriptive and analytic statistical tools using: percentages, means, standard deviations, internal reliability, confidence intervals, factor analysis, $t$-test, ANOVA test and correlation.

Results The results of mean score (scored out of 10 for all scores) and standard deviation theoretical exam in medicine, surgery, gynecology and obstetrics and pediatrics were: $4.55 \pm 1.14,5.62 \pm 1.12,7.15 \pm 0.78,6.31 \pm 1.14$, respectively and no gender difference was observed. While the comparable results in 2016 were: $5.61 \pm 0.92,5.28 \pm 1.08,7.13 \pm 0.92,7.79 \pm 1.22$. Performance, objective structured clinical examination (OSCE) total score were (in the same order) for 2015: $6.30 \pm 0.83,6.66 \pm 0.88,7.02 \pm 0.91,7.81 \pm 0.99$. On comparison of 2015 and 2016 results, minor significant differences were found. A significant positive association was found between graduation score and previous year's scores. Minor significant gender differences were observed in only few assessed parameters.

Conclusion The present study aimed at a correct in depth analysis of the evaluation process and an examination of Kerbala Medical College graduates in two successive years. The results found were very helpful in pointing out the main shortcomings and strength in the examination stations.

Keywords evaluation, education, medical Students, clinical, examination
\end{abstract}

\section{Introduction}

When people hear the term "academic performance", they often think of a person's achievement in getting a bachelor degree. However, several factors indicate a student's academic success. While some may not graduate top of their class, they may hold leadership positions in several student groups or score high on standardized tests where people often consider grades first in evaluating academic achievement. This includes medical schools, which rank students by their scores, awarding special designations such as the joint educational premises for those who graduate first ten in their class. ${ }^{1}$ Scholarship organizations and universities also start by looking at grades, as do some employers, especially when hiring recent graduates. Grades carry more weight in some industries, especially technical professions such as law, medicine and finance. Other industries place less importance on GPA, particularly creative professions such as writing or art and occupations such as sales where people skills are more crucial than technical knowledge.

The traditional approach in medical learning was based on the bucket theory: If medical students are filled with the required foundational knowledge, they are expected to be able to strategically retrieve and direct just the right subsets of that knowledge toward problems faced in clinical practice. ${ }^{2}$ In addition, each student should develop basic clinical skills during undergraduate courses including: disciplines of medical core knowledge, medical ethics, and basic clinical skills of life saving procedures as well as other essential professions like communications, diagnostic and emergency interventional experiences. ${ }^{3}$ It is known that assessment in medical education is essential part and not a step for passing to a higher level. It serves many functions as it doesn't determine what students learn but it guides the process of learning, also it provides students' feedback on where they stand and motivates them to master the material and it show the society and related organizations that doctors are competent. ${ }^{1,4,5}$

Competence in medicine has been defined as "the habitual and judicious use of communication, knowledge, technical skills, clinical reasoning, emotions, values, and reflection in daily practice for the benefit of the individuals and communities being served". ${ }^{1}$ Competence is not an achievement but rather a habit of lifelong learning. ${ }^{6}$ On the other hand, competence is the habitual and judicious use of communication, knowledge, technical skills, clinical reasoning, emotions, values, and reflection in daily practice for the benefit of the individuals and communities being served. Additionally, assessment plays an integral role in helping physicians identify and respond to their own learning needs. Ideally, the assessment of competence (what the student or physician is able to do) should provide insight into the actual performance (what he or she does habitually when not observed), as well as the capacity to adapt to change, find and generate new knowledge, and improve overall performance. ${ }^{1,4}$ Some graduates unfortunately apparently fail acquiring some essential basic skills during undergraduate course. This problem of under competency is not limited to Iraqi medical graduates but also appears in some 
graduates of credited universities and medical schools in developing and developed countries. ${ }^{7,8}$

In the United States, the assessment of medical residents, and increasingly of medical students, is largely based on a model developed by the Accreditation Council for Graduate Medical Education (ACGME). This model uses six interrelated domains of competence: medical knowledge, patient care, professionalism, communication and interpersonal skills, practice-based learning and improvement, and systems-based practice. ${ }^{9}$

Objective structured clinical examination (OSCE) was first described by Harden in $1975,{ }^{10}$ it has an established role in the assessment of the medical undergraduates. OSCE assess history taking, clinical examination, data interpretation procedure or practical skills and communication skills. ${ }^{11-13}$ It represents a valid and reliable tool in medical education for evaluating clinical competence. ${ }^{13}$ OSCE was introduced to test final year candidates in the Council of Arab Board students and later for undergraduate students in Iraq. ${ }^{3,5,14}$ A study had reported overall good student's evaluation and preference of OSCE in Basra medical college. ${ }^{14}$ In the last decade many articles tried to evaluate the level of assessment in medical colleges in Iraq and a national exit examination was suggested. ${ }^{4,5,7,14-20}$

There are 23 medical colleges in Iraq where medical teaching is based on the traditional British teaching system, grant Medicine and Surgery Bachelor certificate. The graduates after passing the final examination are recognized as members of the Iraqi Medical Association and officially assigned as house surgeons (intern resident doctors) serve 24 months rotational training courses in general hospitals. Admission to medical schools is very competitive and is based on performance in the general national high school examination with nearly full mark scores in all branches. To ensure competence in these fields, and according to the instructions of the Ministry of Higher Education, all graduates need to pass a final examination after 6-year study. The examination tests theoretical and clinical aspects including: Long case, short case, Objective Structured Clinical Examination OSCE. ${ }^{3}$

\section{Materials and Methods}

The achievements of the students in the final year examination different sections in Kerbala Medical College for the academic years 2014-2015 and 2015-2016 in addition to cumulative sores for the preceding five years were assessed. The goal was to determine the effectiveness of different of examination methods and the level of performance of the students in each (and for different subgroups) according to examination scores in theoretical and clinical examinations. The clinical part of the examination included: direct observation clinical examination (DOCE), long case (LC), computerized images and video assessment (CIVA), oral examination (VIVA), objective structural clinical examinations stations (OSCE). The data were analyzed using the Statistical Package for Social Sciences version 20 (SPSS-20) at a significance level of .05 through different descriptive and analytic statistical tools using: percentages, means, standard deviations, internal reliability, confidence intervals, factor analysis, $t$-test, ANOVA test, correlation and structural Equation Modeling. Students' achievements in different parts of the final year tests and their cumulative sores for the preceding five years were compared among different gender and in the two studied years (2015 and 2016).

\section{Results}

The number of graduates in 2014/2015 (reported as 2015) was 51 graduates (15 males and 36 females) and in 2015/2016 (reported as 2016) were 71 graduates (27 males and 43 females).

The mean age of the graduate of the Kerbala Medical College was $24.63 \pm 1.822$ year in 2015, and $24.39 \pm 1.011$ year in 2016 with no significant gender difference.

The internal reliability (Cronbach's Alpha), when all examination scores were included was measured and the findings showed that it was 0.88 and 0.86 for 2015 and 2016, respectively. When Cronbach's Alpha was measured for these tests, it was 0.91 for both 2015 and 2016. When Cronbach's Alpha was measured for different branches OSCE examinations separately, the values were all almost acceptable $(>0.6)$.

The mean scores of theoretical examination, direct observation clinical examination (DOCE), or long case (LC), computerized images and video assessment (CIVA), oral examination (VIVA), objective structural clinical examinations stations (OSCE) total scores in 2015 and 2016 showed no significant gender difference (Table 1), while ANOVA test showed no significant difference between the means in the 2 years.

When gender difference was explored, no significant difference was discovered in any part of the assessment (Tables 2 and 3).

\section{OSCE in Medicine}

When the mean difference between OSCE in medicine in the two years was explored, significant differences were discovered in all parts of the assessment except for neurology (Table 4).

\section{OSCE Surgery}

When the mean difference between OSCE in medicine in the 2 years was explored, significant differences were discovered in all parts of the assessment except for a history of jaundice case and X-ray pediatric surgery (Table 5).

\section{OSCE Gynecology and Obstetrics}

When the mean difference between OSCE in the two years was explored, significant differences were discovered in all parts of the assessment except for obstetrics interpretation and two stations short case Examination -short case- (Table 6).

\section{OSCE Pediatrics}

When the mean difference between OSCE in the two years was explored, significant differences were discovered only in history, slides and clinical examination (Table 7).

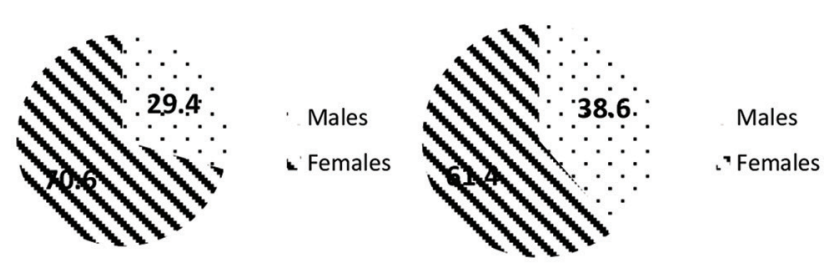

Fig 1. The gender distribution of the graduates from Kerbala Medical College in $2015(n=51)$ and $2016(n=71)$. 


\begin{tabular}{|c|c|c|c|c|c|c|c|c|}
\hline \multirow{3}{*}{ Assessment } & \multicolumn{6}{|c|}{2015} & & \\
\hline & \multicolumn{2}{|c|}{ Medicine } & \multicolumn{2}{|c|}{ Surgery } & \multicolumn{2}{|c|}{ Gynecology and Obstetrics } & \multicolumn{2}{|c|}{ Pediatrics } \\
\hline & Mean & Std. deviation & Mean & Std. deviation & Mean & Std. deviation & Mean & Std. deviation \\
\hline Theoretical examination & 4.55 & 1.14 & 5.62 & 1.12 & 7.15 & 0.78 & 6.31 & 1.14 \\
\hline CIVA & 7.35 & 1.34 & 7.12 & 0.99 & 8.22 & 0.89 & 6.94 & 1.03 \\
\hline DOCE or Long case & 6.08 & 2.09 & 6.77 & 0.95 & & & 6.98 & 1.81 \\
\hline OSCE total Score & 6.30 & 0.83 & 6.66 & 0.88 & 7.02 & 0.91 & 7.81 & 0.99 \\
\hline \multicolumn{9}{|c|}{2016} \\
\hline \multirow{2}{*}{ Assessment } & \multicolumn{2}{|c|}{ Medicine } & \multicolumn{2}{|c|}{ Surgery } & \multicolumn{2}{|c|}{ Gynecology and Obstetrics } & \multicolumn{2}{|c|}{ Pediatrics } \\
\hline & Mean & Std. deviation & Mean & Std. deviation & Mean & Std. deviation & Mean & Std. deviation \\
\hline Theoretical examination & 5.61 & 0.92 & 5.28 & 1.08 & 6.60 & 1.46 & 5.79 & 1.22 \\
\hline CIVA & 6.06 & 1.20 & 6.77 & 0.96 & 7.13 & 0.92 & 6.94 & 2.20 \\
\hline DOCE or Long case & 6.12 & 1.74 & 5.39 & 1.14 & & & 6.94 & 1.17 \\
\hline OSCE total Score & 6.22 & 0.70 & 5.49 & 1.01 & 7.44 & 1.23 & 7.69 & 0.96 \\
\hline
\end{tabular}

\begin{tabular}{|c|c|c|c|c|c|c|c|}
\hline \multirow{2}{*}{ Branch } & \multirow{2}{*}{ Assessment } & \multicolumn{2}{|c|}{ Males } & \multicolumn{2}{|c|}{ Females } & \multirow{2}{*}{$t$-value } & \multirow{2}{*}{ Significance } \\
\hline & & Mean & Std. deviation & Mean & Std. deviation & & \\
\hline \multirow[t]{4}{*}{ Medicine } & Theoretical examination & 5.11 & 1.01 & 4.32 & 1.12 & 2.35 & 0.847 \\
\hline & CIVA & 7.17 & 1.39 & 7.42 & 1.33 & -0.59 & 0.454 \\
\hline & DOCE1 & 5.93 & 2.06 & 6.14 & 2.12 & -0.32 & 0.781 \\
\hline & OSCE total & 6.24 & 0.83 & 6.24 & 0.83 & 0.89 & 0.811 \\
\hline \multirow[t]{4}{*}{ Surgery } & Theoretical E. & 6.08 & 0.96 & 5.43 & 1.15 & 1.91 & 0.337 \\
\hline & CIVA & 7.00 & 0.85 & 6.68 & 0.98 & 1.13 & 0.379 \\
\hline & Long Case & 7.18 & 1.12 & 7.10 & 0.95 & 0.26 & 0.375 \\
\hline & OSCE total & 6.62 & 0.94 & 6.67 & 0.87 & -0.19 & 0.393 \\
\hline \multirow{3}{*}{$\begin{array}{l}\text { Gynecology and } \\
\text { Obstetrics* }\end{array}$} & Theoretical E. & 7.30 & 0.75 & 7.15 & 0.79 & 0.62 & 0.965 \\
\hline & CIVA & 8.26 & 0.89 & 8.29 & 0.74 & -0.10 & 0.669 \\
\hline & OSCE total & 7.12 & 0.84 & 7.12 & 0.84 & -1.03 & 0.055 \\
\hline \multirow[t]{4}{*}{ Pediatrics } & Theoretical examination & 5.99 & 1.11 & 6.45 & 1.14 & -1.33 & 0.542 \\
\hline & CIVA & 7.14 & 2.11 & 8.33 & 1.39 & -2.37 & 0.302 \\
\hline & Long Case & 7.10 & 1.04 & 6.87 & 1.04 & 0.72 & 0.639 \\
\hline & OSCE total & 7.63 & 1.36 & 7.89 & 0.79 & -0.85 & 0.067 \\
\hline
\end{tabular}

* There was no long case examination in gynecology and obstetrics.

\section{Six years Summative Scores}

For 2015, the mean for the first three study years were around 3.00 out of 5 and for the fourth year the mean was 12.75 \pm 1.24 out of 20 and $16.65 \pm 2.04$ out of 25 for the fifth year and $26.36 \pm 2.72$ out of 40 for the sixth year, while the mean of the sum (total graduation score) was $65.72 \pm 6.77$ (Table 8).

For 2016 graduates, the means were slightly lower but no significant difference was found from 2015 mean score. The mean for the first three study years were similarly around 3.00 out of 5 and for the fourth year the mean was $12.38 \pm 1.27$ out of 20 and $16.98 \pm 1.83$ out of 25 for the fifth year and $25.91 \pm 2.61$ out of 40 for the sixth year, while the mean of the sum (total graduation score) was $64.88 \pm 6.57$ (Table 9).

\section{Structural Equation Model (SEM)}

Analysis of examination sections results using SEM showed the different regression weight subjected by each section of the examination on the total graduation score (Figure 4). A model for the cumulative results showed similarly the regression weight of each year score (Figure 5).

\section{Discussion}

Relatively few studies provide detailed comparative analysis of medical college graduates' performance. ${ }^{2}$

The results of the present study showed the importance of feedback resulting from the analysis of the detailed 


\begin{tabular}{|c|c|c|c|c|c|c|c|}
\hline \multirow{2}{*}{ Branch } & \multirow{2}{*}{ Assessment } & \multicolumn{2}{|c|}{ Males } & \multicolumn{2}{|c|}{ Females } & \multirow{2}{*}{$t$-value } & \multirow{2}{*}{ Significance } \\
\hline & & Mean & Std. deviation & Mean & Std. deviation & & \\
\hline \multirow[t]{4}{*}{ Medicine } & Theoretical examination & 5.74 & 0.84 & 5.53 & 0.97 & 2.35 & 0.850 \\
\hline & CIVA & 6.39 & 1.17 & 5.85 & 1.18 & -0.59 & 0.454 \\
\hline & DOCE & 6.08 & 1.82 & 6.14 & 1.71 & -0.32 & 0.781 \\
\hline & OSCE total & 6.28 & 0.76 & 6.18 & 0.67 & 0.89 & 0.811 \\
\hline \multirow[t]{4}{*}{ Surgery } & Theoretical examination & 5.58 & 1.06 & 5.08 & 1.07 & 1.91 & 0.337 \\
\hline & CIVA & 6.80 & 0.81 & 6.76 & 1.05 & 1.13 & 0.381 \\
\hline & Long Case & 5.68 & 1.24 & 5.21 & 1.06 & 0.26 & 0.375 \\
\hline & OSCE total & 5.89 & 0.71 & 5.24 & 1.09 & -0.19 & 0.397 \\
\hline \multirow{3}{*}{$\begin{array}{l}\text { Gynecology and } \\
\text { Obstetrics* }\end{array}$} & Theoretical examination & 7.00 & 0.90 & 7.21 & 0.93 & 0.79 & 0.959 \\
\hline & CIVA & 7.48 & 1.34 & 7.42 & 1.17 & 0.22 & 0.926 \\
\hline & OSCE total & 7.42 & 0.71 & 7.22 & 0.73 & -0.94 & 0.058 \\
\hline \multirow[t]{4}{*}{ Pediatrics } & Theoretical examination & 5.53 & 1.43 & 5.95 & 1.05 & -1.33 & 0.540 \\
\hline & CIVA & 6.77 & 1.34 & 6.97 & 2.50 & -1.70 & 0.303 \\
\hline & Long Case & 6.91 & 1.65 & 7.05 & 1.05 & 0.72 & 0.639 \\
\hline & OSCE total & 7.83 & 0.87 & 7.61 & 1.01 & -0.85 & 0.067 \\
\hline
\end{tabular}

*There was no long case examination in gynecology and obstetrics.

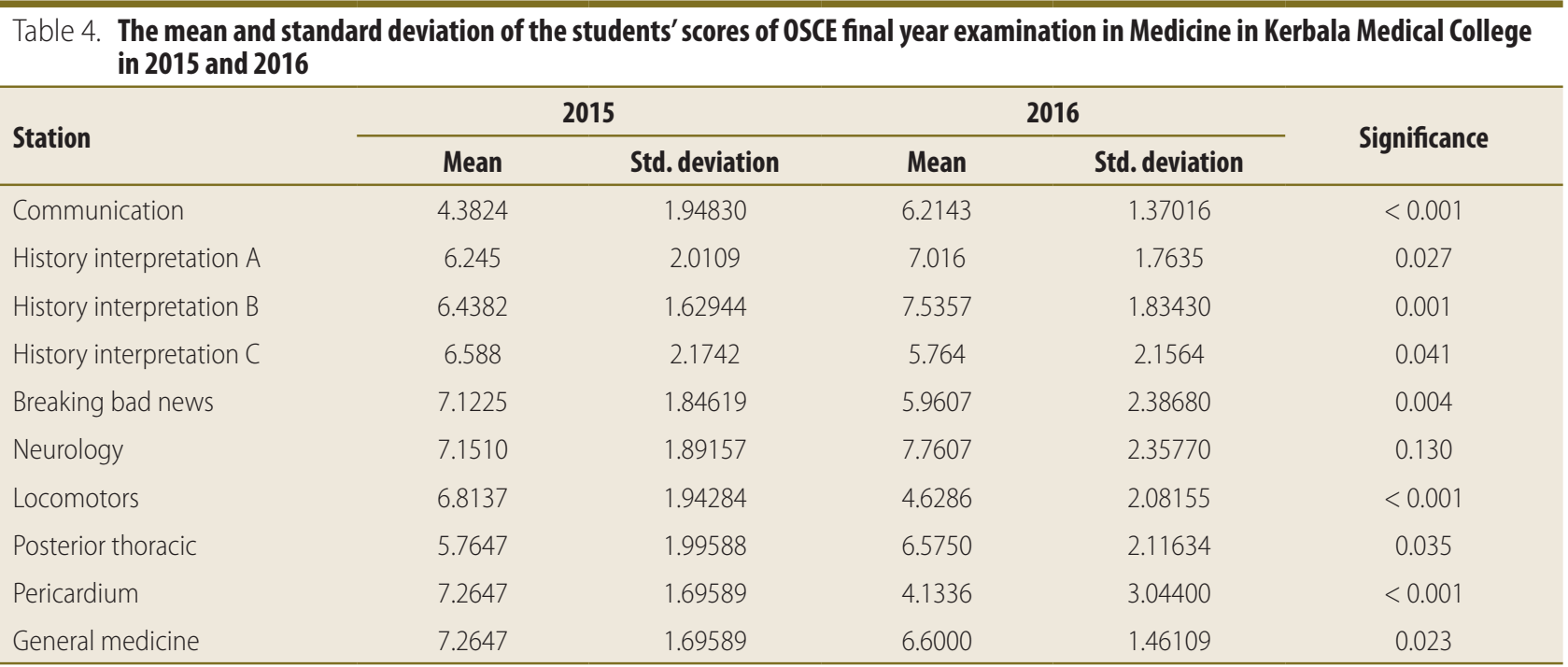

examination results which affect the quality of assessment in the future. The overarching goal of educational reform should be to transform medical assessment from passive observation to active process contributing both in curriculum correction and improvement of assessment. Detailed analysis of the results and possible causes for differences were discussed with the responsible departments in the college to reach for planning of improved assessment in the next year.

An analysis of radiology course in the Tikrit Medical College, reported a mean of 82 and CI 66-97.8 and only $6.3 \%$ of the participants got the "honors" -two standard deviation above the mean-, while $6.7 \%$ of the participants were two standard deviations below the mean in the written test. For the written and practical test, the range of the scores was tighter, $65-96 \%$, and the mean of $80.5 \%$ and a standard deviation of 5.3, the "honors" and failure rates were approximately $5 \% .^{20}$

OSCE value was estimated in two articles in Basra medical college. In the first, the students' perception was reported to be positive. The selection of suitable assessment or evaluation depends on its validity (a measure of the extent to which the test actually measure what is intended to measure), reliability (a measure of whether the assessment or test is consistent and accurate; examines the extent to which factors such as examiners, questions, occasions affect the marks or scores awarded) and practicability was proved. ${ }^{5,14}$

Academic performance of medical students in western Australia and in Indonesia was found to be significantly 


\begin{tabular}{|c|c|c|c|c|c|}
\hline \multirow{2}{*}{ OSCE examination } & \multicolumn{2}{|c|}{2015} & \multicolumn{2}{|r|}{2016} & \multirow{2}{*}{ Significance } \\
\hline & Mean & Std. deviation & Mean & Std. deviation & \\
\hline History of jaundice case & 5.99 & 1.92 & 6.21 & 1.05 & 0.429 \\
\hline Surgical examination A & 5.86 & 1.82 & 4.93 & 1.76 & 0.006 \\
\hline Hand work & 8.11 & 1.74 & 7.20 & 1.06 & 0.001 \\
\hline Surgical examination B & 5.22 & 2.94 & 3.54 & 1.83 & $<0.001$ \\
\hline Burns management & 6.41 & 2.59 & 3.89 & 3.69 & $<0.001$ \\
\hline Pictures interpretation & 5.12 & 3.23 & 3.86 & 2.98 & 0.028 \\
\hline Orthopedic X-ray & 7.08 & 2.62 & 5.70 & 2.87 & 0.008 \\
\hline General surgery instruments & 8.19 & 1.03 & 6.43 & 1.87 & $<0.001$ \\
\hline CT Urology & 9.27 & 1.70 & 6.36 & 3.11 & $<0.001$ \\
\hline Hand suturing & 8.04 & 1.48 & 6.57 & 2.09 & $<0.001$ \\
\hline X-ray pediatric surgery & 5.61 & 3.16 & 6.24 & 3.52 & 0.309 \\
\hline X-ray Urology & 5.15 & 1.91 & 7.74 & 3.13 & $<0.001$ \\
\hline
\end{tabular}

Table 6. The mean and standard deviation of the of the students' scores of OSCE final year examination in Gynecology and Obstetrics in Kerbala Medical College in 2015 and 2016

\begin{tabular}{lcccccc}
\hline \multirow{2}{*}{ OSCE examination } & \multicolumn{2}{c}{$\mathbf{2 0 1 5}$} & \multicolumn{2}{c}{$\mathbf{2 0 1 6}$} & \multirow{2}{*}{ Significance } \\
\cline { 2 - 5 } & Mean & Std. deviation & Mean & Std. deviation & \\
\hline Gynecology history & 7.03 & 1.90 & 7.33 & 1.25 & $<0.001$ \\
Gynecology interpretation & 8.67 & 1.49 & 6.33 & 1.29 & $<0.001$ \\
Obstetrics history & 6.38 & 1.54 & 8.02 & 1.86 & $<0.001$ \\
Obstetrics interpretation & 7.54 & 1.59 & 8.19 & 1.38 & 0.697 \\
Gynecological examination & 7.02 & 1.35 & 6.52 & 1.71 & 0.120 \\
Two stations short case examination & 8.29 & 1.31 & 7.37 & 2.08 & 0.353 \\
\hline
\end{tabular}

\begin{tabular}{|c|c|c|c|c|c|}
\hline \multirow{2}{*}{ OSCE examination } & \multicolumn{2}{|c|}{2015} & \multicolumn{2}{|c|}{2016} & \multirow{2}{*}{ Significance } \\
\hline & Mean & Std. deviation & Mean & Std. deviation & \\
\hline Clinical examination A & 8.15 & 1.44 & 8.14 & 1.19 & 0.963 \\
\hline Data interpretation A & 6.48 & 2.23 & 7.36 & 3.38 & 0.110 \\
\hline Counseling & 7.12 & 3.25 & 7.85 & 1.98 & 0.128 \\
\hline Data interpretation B & 8.19 & 1.71 & 7.78 & 1.79 & 0.210 \\
\hline Community & 7.76 & 1.27 & 8.38 & 2.23 & 0.076 \\
\hline Instruments and drugs & 8.35 & 2.05 & 8.70 & 1.49 & 0.280 \\
\hline History & 8.80 & 1.65 & 7.08 & 1.42 & 0.000 \\
\hline Clinical examination B & 8.30 & 1.37 & 7.64 & 1.35 & 0.009 \\
\hline Slides & 7.98 & 1.70 & 6.94 & 2.20 & 0.006 \\
\hline Development & 6.98 & 1.81 & 6.94 & 1.51 & 0.898 \\
\hline
\end{tabular}

correlated with their performance as a Junior Doctor $(r=0.229, \mathrm{P}=0.002)$, and with their mean scores on entering medical college. ${ }^{22,23}$ Blackman, ${ }^{23}$ evaluated the influence of students score in different study years on post graduate performance. The effects of GPA scores with reference to Fig. 3, it can be seen that the grade point average scores obtained by students in their undergraduate studies (LV6) has a direct influence on their subsequent achievement on the clinical assessment tasks. A positive path coefficient exists between these two variables $(0.17)$ which indicates that students with higher grade point averages in their undergraduate studies overall achieve at a higher level on the clinical examination in their third year of medical studies. The loadings for the GPA scores obtained in the first $(0.88)$ second $(0.92)$ or third 


Table 8. The mean and standard deviation of the students' scores for the six years
summative scores by gender in Kerbala Medical College graduates in $\mathbf{2 0 1 5}$

\begin{tabular}{|c|c|c|c|c|c|c|}
\hline \multirow{2}{*}{ Year } & \multicolumn{2}{|r|}{ Males } & \multicolumn{2}{|r|}{ Females } & \multicolumn{2}{|r|}{ Total } \\
\hline & Mean & Std. deviation & Mean & Std. deviation & Mean & Std. deviation \\
\hline First & 3.37 & 0.37 & 3.33 & 0.38 & 3.35 & 0.37 \\
\hline Second & 3.12 & 0.39 & 3.02 & 0.39 & 3.06 & 0.39 \\
\hline Third & 3.24 & 0.50 & 3.17 & 0.45 & 3.20 & 0.47 \\
\hline Fourth & 12.49 & 1.36 & 12.32 & 1.23 & 12.38 & 1.27 \\
\hline Fifth & 17.24 & 1.81 & 16.81 & 1.84 & 16.98 & 1.83 \\
\hline Sixth & 26.50 & 2.78 & 25.53 & 2.46 & 25.91 & 2.61 \\
\hline Total & 65.96 & 6.86 & 64.18 & 6.37 & 64.88 & 6.57 \\
\hline
\end{tabular}

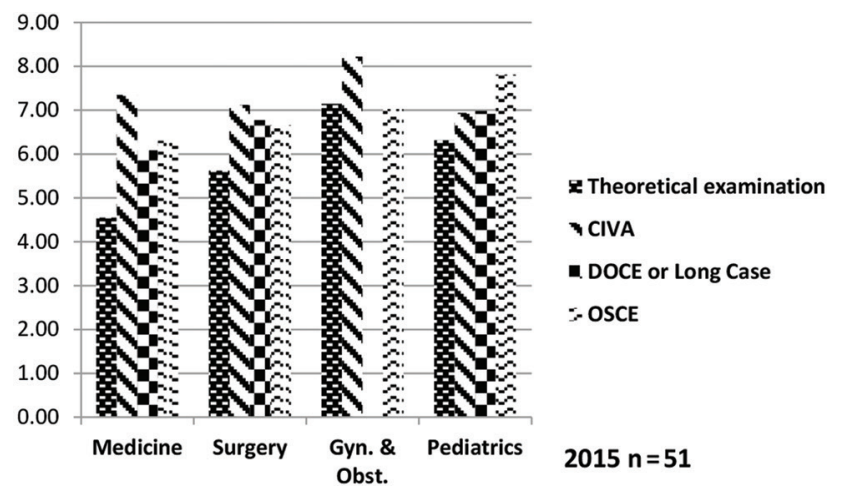

Fig 2. The mean of the students' scores in the main final year examination parts in Kerbala Medical College in 2015.

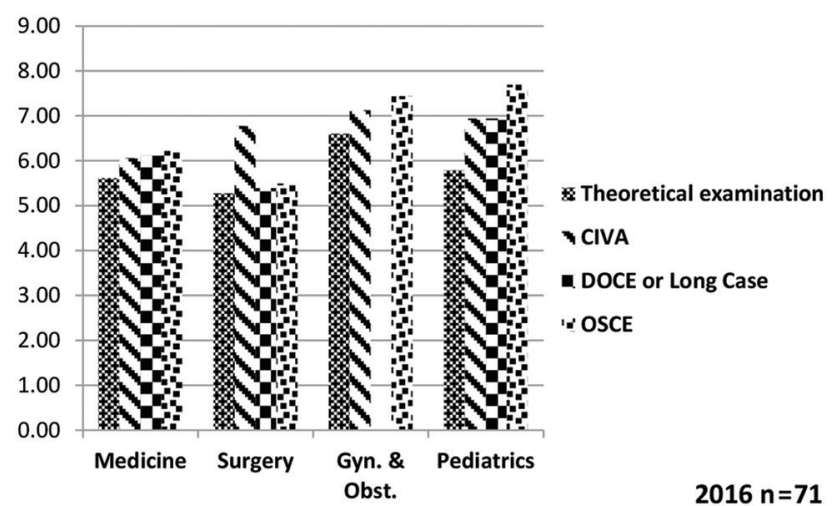

Fig 3. The mean of the students' scores in the main final year examination parts in Kerbala Medical College in 2016. years $(0.78)$ of study are an indication that there is little difference between the contributions to OSCE performance made by the different years of prior study. In the present study a direct association between the scores obtained in the previous study years and the final graduation score was clear (Figure 4). However, low to moderate correlation of undergraduate assessment with postgraduate training performance was reported by other studies. ${ }^{24}$

No gender difference was found in achievements in all parts of the final year examination in Kerbala Medical College and this was similar to the findings in many studies in other countries. ${ }^{25-27}$ However, female students were consistently found in the literature to perform better than males in their medical training which might be related to higher motivation. A systematic review by Ferguson and his colleagues reported that a growing body of research explores whether different motivational, academic, and demographic factors influence the performance of male and female women where motivation seems to be important. $^{21}$ The reason behind failing to find any gender difference in the present study might be related to the higher proportion of females in the sample or some other reasons that need further investigation.

Environmental factors and personal characteristics might be responsible for the differences discovered between the two years. Differences in raters' grading could introduce variability into the measurement of a student's performance and thus make the measurement less reliable. Additionally, specific attributes of the student, evaluator, or environment in which the interaction took place might affect the student's scores by introducing systematic 


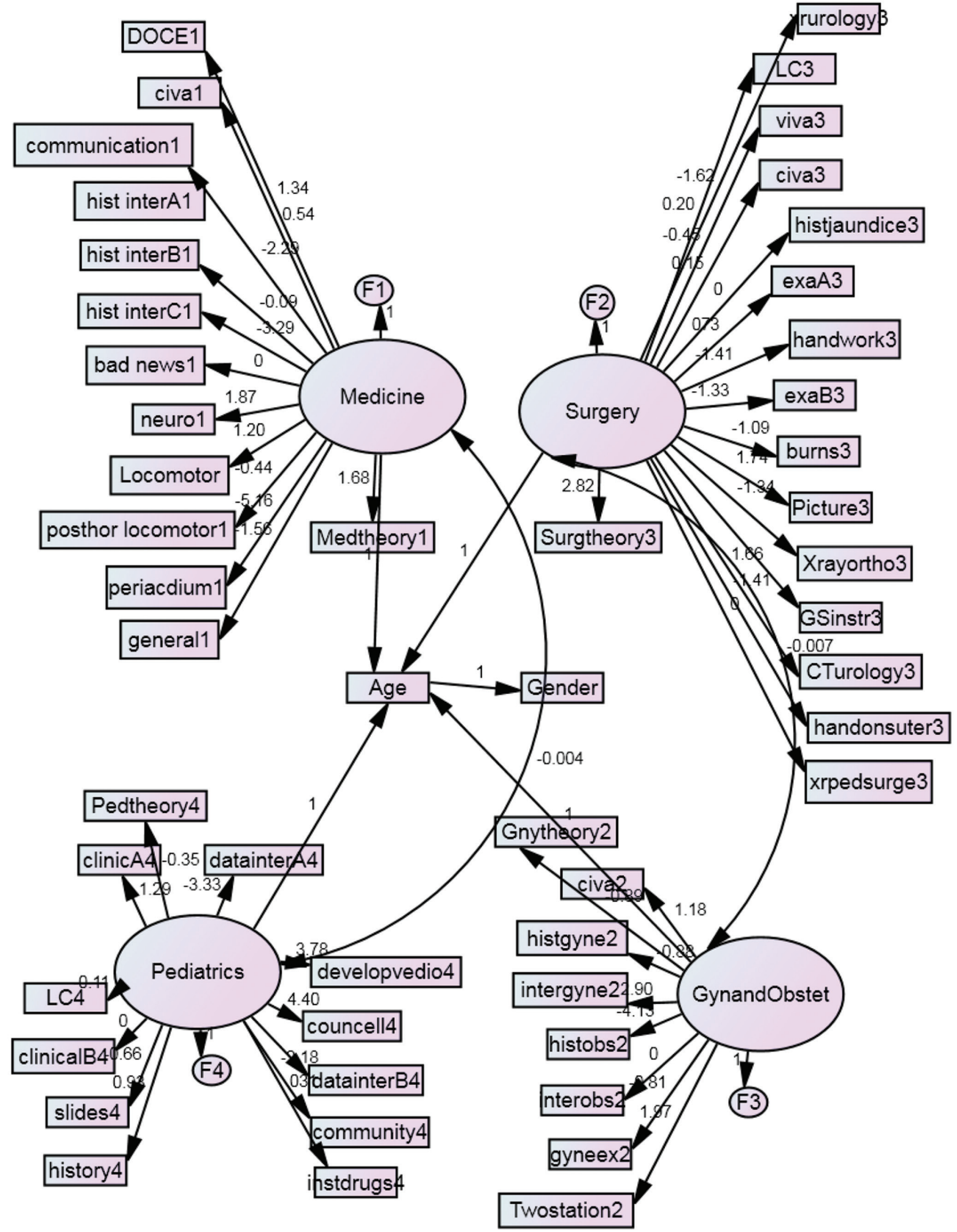

Fig 4. Structural Equation Model of all input variables in different sections of final examination in Kerbala Medical College in 2016. 


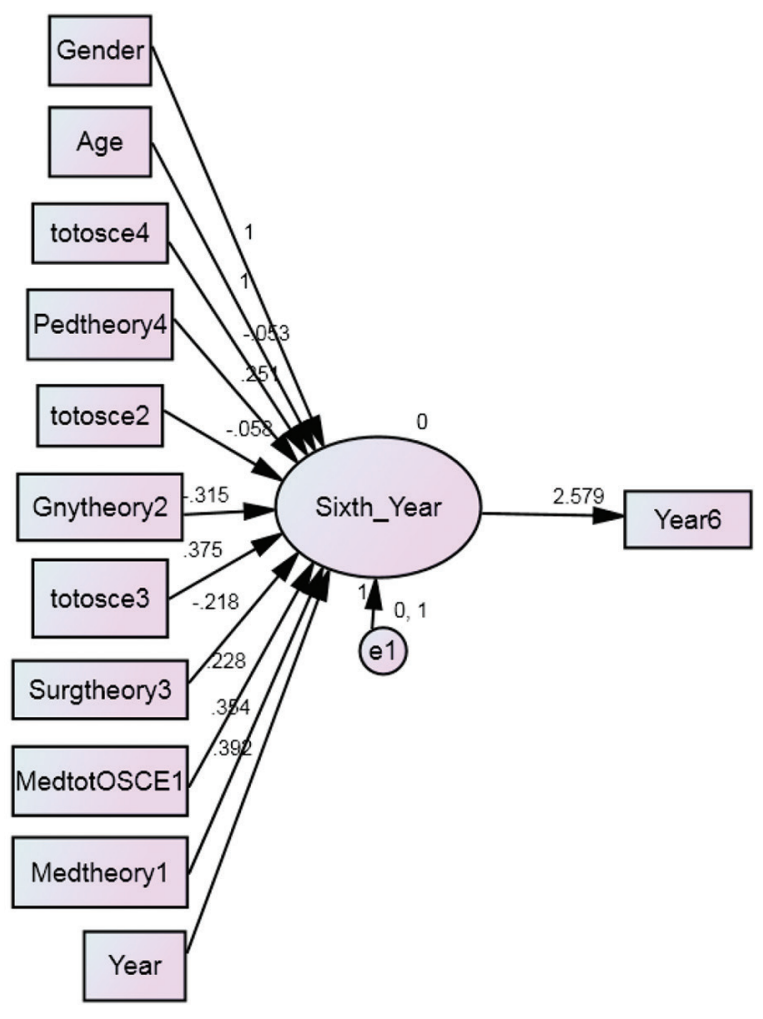

Fig 5. Structural Equation Model of all input variables in different main branches of final examination in Kerbala Medical College in 2016. differences into the measurement, further decreasing the reliability of the system. ${ }^{25}$

Multivariate regression analysis approach to studying predictors of success in medical training was suggested in a systematic review of about twenty two thousands medical students ${ }^{(21)}$. Predictors are likely to be inter-correlated, as are outcome measures. Additionally, learning across the medical degree occurs over time, and time series analyses and models that allow for prediction of change over time would also be a useful approach in exploring trend effects. The use of SEM procedures, as well as hierarchical structural models using structural and time series components, was also beneficial to develop our understanding of the prediction of performance. ${ }^{21,26}$

\section{Conclusions}

The evaluation process and examination section yields correct in depth findings resulted from analysis of Kerbala Medical College graduates in two successive years (2015 and 2016). On practical base, the results found were very helpful in pointing out the main shortcomings and strength in the examination stations and to plan for more accurate assessment for the graduates.

\section{Conflict of Interest}

None.

\section{References}

1. Epstein RM. Assessment in medical education. New Eng J Med. 2007;356:387-396.

2. Wood EJ. The problems of problem-based learning. Biochem Edu. 1994;22:78-82.

3. AlHelli AA, Abdul-Sahib M. The sequential feedback of Iraqi medical graduates performance. J Kerbala University. 2013;11:13-25.

4. Amin Z, Chong Y, Khoo H. Towards better practices in medical student assessment. Annals-Academy Of Medicine Singapore. 2005;34:471.

5. Abdulla MA. OSCE, Things to be said. Basrah J Surg. 2010;16:4-6.

6. Leach DC. Competence is a habit. JAMA. 2002;287:243-244.

7. AlHelli A. Evaluation of Medical Colleges` Graduates in Iraq. Karbala Journal of Medicine. 2010;3:919-25.

8. Premadasa I, Shehab D, Al-Jarallah KF, Thalib L. Frequency and confidence in performing clinical skills among medical interns in Kuwait. Medical teacher. 2008;30:e60-e65.

9. Kavic MS. Competency and the Six Core Competencies. JSLS : J Soc Laparoendoscopic Surg. 2002:6:95-97.

10. Harden RM, Gleeson F. Assessment of clinical competence using an objective structured clinical examination (OSCE). Med Edu. 1979;13:39-54.

11. Pell G, Fuller R, Homer M, Roberts T. How to measure the quality of the OSCE: A review of metrics-AMEE guide no. 49. Medical teacher. 2010;32:802-11.

12. Van Der Vleuten CP, Schuwirth LW. Assessing professional competence: from methods to programmes. Med Edu. 2005;39:309-17.

13. Walsh M, Bailey PH, Koren I. Objective structured clinical evaluation of clinical competence: an integrative review. J Advan Nur. 2009;65:1584-95.

14. Abdulla, M A. Student's perception of objective structured clinical examination (OSCE) in surgery at Basrah College of Medicine. Basrah J Surg. 2012:18:21-5.

15. Sarhat A R, Abedalrahman S K. Toward Iraqi National Medical Licensing Examination. Diyala J Pure Sci. 2010;6:77-84

16. Abdulghani H M, Al-Drees A A, Khalil M S, Ahmad F, Ponnamperuma G G, Amin Z. What factors determine academic achievement in high achieving undergraduate medical students? A qualitative study. Medical Teacher. 2014;36 Suppl 1:S43-8.

17. Al-Shamsi MM. Evaluation of the Final Year Medical Students by External Examiners. Kerbala J Med. 2007;1:243-247.

18. Al-Jobori, M, Abbas, A. Assess the quality of higher education programs as a framework for the success of the education process. AL-Qadisiya J Admin Econ Sci. 2016;18:34-56

19. Jasim. Opinions of Nineveh medical college students regarding current medical educational methods and teaching strategies. Med J Tikrit. 2013;19(1):114-119.

20. Younis SN. Improving undergraduate education in Radiology. Tikret J Pharm Sci. 2011;7:130-4

21. Ferguson E, James D, Madeley L. Factors associated with success in medical school: systematic review of the literature. BMJ. 2002;324:952-957.

22. Carr SE, Celenza A, Puddey IB, Lake F. Relationships between academic performance of medical students and their workplace performance as junior doctors. BMC Med Edu. 2014;14:1

23. Blackman IR, Darmawan I. Graduate-entry medical student variables that predict academic and clinical achievement. Int Edu J. 2004;4:30-41.

24. Hamdy H, Prasad K, Anderson MB, Scherpbier A, Williams R, Zwierstra R, et al. BEME systematic review: predictive values of measurements obtained in medical schools and future performance in medical practice. Medical Teacher. 2006;28:103-16.

25. Spielvogel R SZ, Beckett L, Latimore D. Sources of variability in medical student evaluations on the internal medicine clinical rotation. International Journal of Medical Education. 2012;3:245-51.

26. McManus I, Richards P. Admission for medicine in the United Kingdom: a structural model of background factors. Medical Education. 1986;20:181-6.

27. Lewinski P. Effects of classrooms' architecture on academic performance in view of telic versus paratelic motivation: a review. Front Psychol. 2015;6:746.

This work is licensed under a Creative Commons Attribution-NonCommercial 3.0 Unported License which allows users to read, copy, distribute and make derivative works for non-commercial purposes from the material, as long as the author of the original work is cited properly. 